\title{
Mechanical Properties and Cost-Minimized Design of 6-liter PET Bottle Using Finite Element Method
}

\author{
Kunlapat THONGKAEW ${ }^{1, *}$ and Thanwit NAEMSAI ${ }^{2}$ \\ ${ }^{I}$ Department of Industrial Engineering, Faculty of Engineering, Prince of Songkla University, \\ Songkhla 90112, Thailand \\ ${ }^{2}$ Department of Mechanical Engineering, Faculty of Engineering, Rajamangala University of Technology \\ Srivijaya, Songkhla 90000, Thailand
}

("Corresponding author's e-mail: kunlapat.t@psu.ac.th)

Received: 2 March 2019, Revised: 22 May 2019, Accepted: 29 June 2019

\begin{abstract}
Over the years, plastic water bottle manufacturing, especially PET (Polyethylene terephthalate) bottle has been steadily increasing due to its toughness, transparency, and chemical properties. However, most manufacturers have to spare time, and cost, verifying their prototypes in accordance to the Thai Industrial Standard (TIS) before any mass production can start. This paper aims to overcome some of these problems by using Finite Element Method (FEM) to study bottle mechanical properties, particularly maximum stress and deformation that can be employed to evaluate performance and optimal thickness. From simulation results the optimal thickness of a 6-liter bottle, that its maximum stress can still be kept under critical value, is $0.45 \mathrm{~mm}$. The thinner and lighter bottle reduces the amount of material usage. The FEM simulation also speeds up and alleviates some necessary testing procedures in a prototype designing process.
\end{abstract}

Keywords: PET bottle, Finite element method, Material reduction, Bottle design, Cost-minimized

\section{Introduction}

Potable water in Thailand is said to be obtained from four main origins: rain water, groundwater, tap water, and bottled water. According to Thailand's National Statistical Office [1], in 2018, bottled water was the second highest drinking water with the total of $31.6 \%$, just behind rainwater at $34.6 \%$. There are a high number of bottled water companies that operate in Thailand and competition is very high. Many manufacturers court potential customers to buy their products using marketing ploys, such as advertisement, promotion, discount, and the like, while others focus on reducing production costs from the raw material used. For the latter, bottle design, especially in achieving an optimum weight, can help minimize material costs while providing the required quality and reliability. In water bottle manufacturing processes, bottle quality must comply with the Thai Industrial Standard (TIS 998) [2] before production can commence. These often take time in the testing, verification and certification of bottle prototype mechanical properties such as maximum stress and maximum strain. Even though a prototype is finally acceptable, the amount of material usage may not have been optimized. Researches to tackle this problem are mainly conducted using Finite Element Method (FEM) to simulate, instead of actual costly and timeconsuming trial-and-error experiments. Qingchun et al. [3] applied FEM using ABACUS to analyses bucking load and stress distribution of the PET bottle for lightweight design of the PET bottle.

In the design of water bottle, there are three major factors significantly affecting the bottle strength, including bottle shape, bottle pattern and bottle thickness. Gulati et al. [4] proposed that a FEM tool for rapidly modeling blow-moulds for the fabrication of PET bottles. A parameterized generator for decorative tiling patterns allowed even a novice user to quickly create a design for a customized plastic 
bottle. Then, Vladić et al. [5] presented that PET packaging offered diverse possibilities for communication on relation manufacturer-consumer. The bottle shape must be utilized to the maximum of their potential in order to produce best PET packaging possible. For the bottle thickness, several studies indicated that the bottle strength was proportional to bottle thickness [6-8]. Allahkarami et al. [9] applied a micro X-ray tomography method for measuring the thickness distribution of the bottle base to reduce material used. Furthermore, the mechanical properties in order to explore the feasibility of weight reduction of plastic water bottles [6-8]. Recently, Naemsai and Thongkaew [10] studied geometrical factors of 6-liter PET bottle using finite element method and response surface method approaches in order to optimize the bottle shape. From the result, the optimal bottle shape included: the neck angle of $115^{\circ}$, the shoulder angle of $121^{\circ}$, the ripple width of $4.6 \mathrm{~mm}$, the ripple depth of $2.3 \mathrm{~mm}$ and the distance between ripple of $27.4 \mathrm{~mm}$. This numerical method has also been used to design parameters in evaluating optimal dimensions for petaloid base and neck of water cooler [11,12].

Some researchers have studied the properties of PET bottles during moulding process $[8,13,14]$. Demirel and Daver [8] investigated the material distribution, top load and burst resistance of the PET bottles under different moulding processing conditions, and found that the bottle's strength was introduced biaxial orientation of PET molecules. Sun et al. [13] analyzed the effects stretch speed, preblowing pressure, and blowing pressure on the material thickness distribution of PET beverage bottles through FEM for the purpose of optimization of molding bottle. Krimpenis and Tsakanikas [14], designed PET and PP bottles by focusing on the blow molds under the conditions of mold manufacturing cost and quality of the produced plastic bottles. It was found that thermal conductivity, durability, hardness, stiffness and roughness of the molds were the major influence of the bottles manufacturing process efficiency.

It can be noticed from previous publications that the bottle thickness is the significant parameter of the bottle design both strength and economic analyses. The analysis of bottle design has been conducted during moulding process and after, which most researches have focused on 0.6-liter water bottle, 1.5-liter water bottle and carbonated soft-drink bottle. Few researches, however, have conducted on 6-liter water bottle [10]. Packaging and stacking of bottles for transportation, together with individual handle on each bottle, make it uniquely different from those of smaller bottles. It is thus the aim of this project to employ FEM to design the 6-liter plastic water bottle; evaluating its mechanical properties to derive at an optimal amount of material while saving time in the process.

\section{Materials and methods}

A plastic water bottle comes in many shapes, sizes, and materials; each application has its own quality issues, e.g. bottle preparation before bottling, packaging of finished product and its distribution system. Plastic water bottles are commonly made from three types of polymers: polycarbonate (PC), high density polyethylene (HDPE), and polyethylene terephthalate (PET). Most plastic water bottles are made from PET because of its strong, light, impact resistant, naturally transparent, and completely recyclable properties. The PET bottles are generally made from injection stretch blow moulding process that is one of three main types of blow moulding process: extrusion blow moulding (EBM), injection blow moulding (IBM) and injection stretch blow moulding (ISBM). The injection stretch blow moulding process is that the material is injected to form a preform and then it is blown to the shape. PET bottle manufacturing is best suited for ISBM process [15] because it has an ability to stretch the preform in both the radial and axial direction. The stretching increases the tensile strength, barrier properties, drop impact, clarity, and top load strength for the bottle. Thai Industrial Standard 998 (TIS 998) [2] sets many regulations for plastic drinking containers inclusive of plastic type (PET, PC and PE, etc.), size of container, shape, label, packaging, and mechanical properties. This paper, however, focuses particularly on the mechanical properties in accordance with the Standard: top load capacity, stress cracking resistance of the bottle, and strength of the bottle handle. 


\section{Modelling}

The three parameters studied, as aforementioned, involve top load capacity, stress cracking resistance of the bottle and strength of the bottle handle. For top load testing, the external load used in this paper is that of a 4-layer stacked bottle package on top of the tested specimen, that is a 5-layer stacking configuration. This loading, to cater for uncontrolled and/or unexpected load such as transportation and storage, is one layer more critical than the TIS 998 Standard's defined top load of 3 layers [2]. For stress cracking resistance, the stress-strain curve of the bottle subjected to an incremental and continuous loading is studied. For the strength of bottle handle, the external load is derived from the bottle weight.

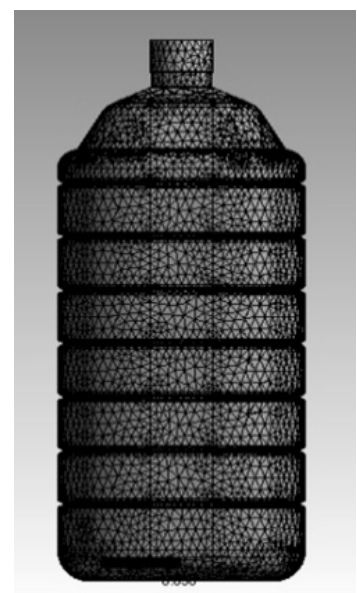

(a)

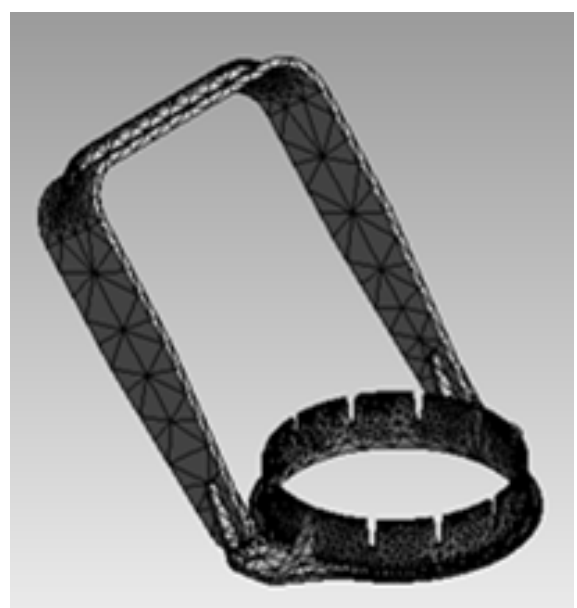

(b)

Figure 1 Meshes created for FEM analyses: (a) bottle body, and (b) bottle handle

The 6-liter water bottle was simulated via Finite Element Analysis (FEA) under ANSYS software [16]. Details of the 6-liter bottle design were firstly obtained from production drafting of SolidWork, a computer aided design software. The bottle and handle were then generated in ANSYS for mechanical property analyses. Tetrahedral element meshes were generated for the models; 122,159 elements for the bottles and 29,438 elements for the handle, as shown in Figure 1. These had been found by the researchers from the minimal mesh sizing for the sufficiently precise result required (grid independency). A largest mesh size length of $0.5 \mathrm{~mm}$ was adopted because the ripple shapes of the bottle are not simple. Material specifications of PET [8], the material for the bottle body, include: a Young's Modulus of 2.9 $\mathrm{GPa}$, a Poisson's ratio of 0.40 , and a density of $1200 \mathrm{~kg} / \mathrm{m}^{3}$. For the bottle handle, which is made from PE, the specifications [17] are: a Young's Modulus of $1.1 \mathrm{GPa}$, a Poisson's ratio of 0.42 and a density of $950 \mathrm{~kg} / \mathrm{m}^{3}$. In the FEA of these models, static solution parameters were set in the ANSYS software. The selected method was a linear static nature. Boundary conditions of the models are described in bottle handle and bottle body sections. For ease and continuity, those for the bottle handle are described first, followed by that for the bottle.

Figure 2 shows boundary conditions for the bottle handle in ANSYS for the strength analysis. The bottle and water weight of $59.91 \mathrm{~N}$ was applied at the center of the handle (the center of the shaded area in Figure 2a). The handle was restrained by the circular contact area between the bottle and the handle (the shaded area in Figure $\mathbf{2 b}$ ). 


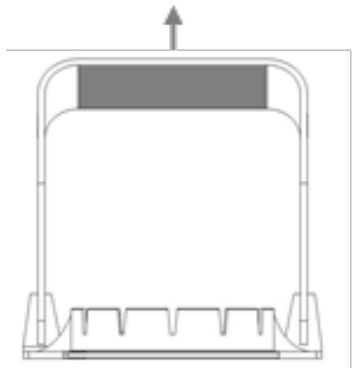

(a)

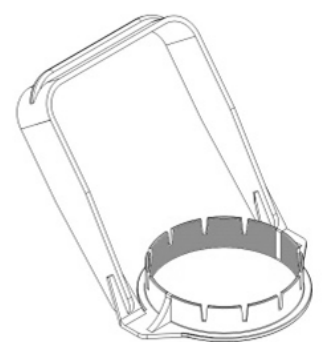

(b)

Figure 2 Load application and restraint on the bottle handle: (a) point of loading; (b) load transfer area.

Simulation of the bottle body could be analyzed under a symmetrical condition because the load vector component and the restrained boundary are both in symmetry. The bottom of the bottle, the shaded area in Figure 3a, was securely restrained. In the top load test (Figure 3b) a sudden top load of $245.25 \mathrm{~N}$, from the assumed 4-stack weight, was applied in the simulation while the inner wall of the bottle in Figure 3c was subjected to the hydrostatic water pressure within the bottle. The water pressure at any point was calculated by the program and a maximum water pressure of $3,305 \mathrm{~N} / \mathrm{m}^{2}$ could be calculated from the maximum height of water in the bottle of $337 \mathrm{~mm}$. In the stress cracking resistance test, conditions for simulation and for the actual experiment are similar to the top load test except that the external load was gradually increased until the bottle failed. These results were to be used in the validation of the simulation and to derive at the maximum stress to be employed in the actual design. The top load simulation testing result according to TIS code can only be assured of its application if validation is proven valid.

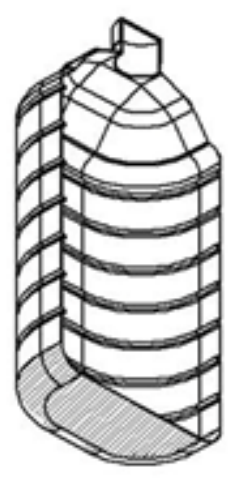

(a)

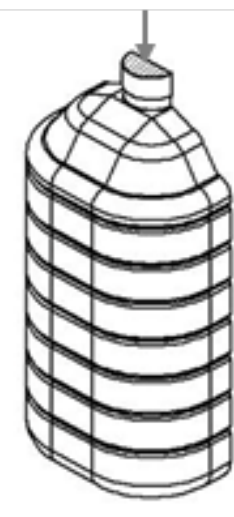

(b)

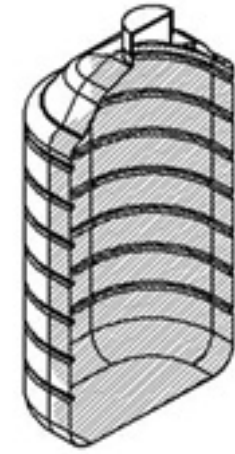

(c)

Figure 3 Restraint and loads: (a) bottle bottom restraint, (b) top load application, (c) hydrostatic pressure in the bottle. 
http://wjst.wu.ac.th

\section{Experiment}

The experimental top load testing, depicted in Figure 4, was conducted using an Instron machine, an instrument commonly used in compression test, tensile test, and flexural test [18]. The specimen was subjected to a downward by $0.5 \mathrm{~mm}$ incremental deformation from the top loading, and then the relationship between load and deformation were recorded. After that the experimental result was presented in force versus deformation graph in order to determine point of failure load or fracture. In addition, a statistical test was also carried out to measure the significance. The t-test was applied to compare the average difference between two groups [19], indicated good agreement at $95 \%$ confidence interval.

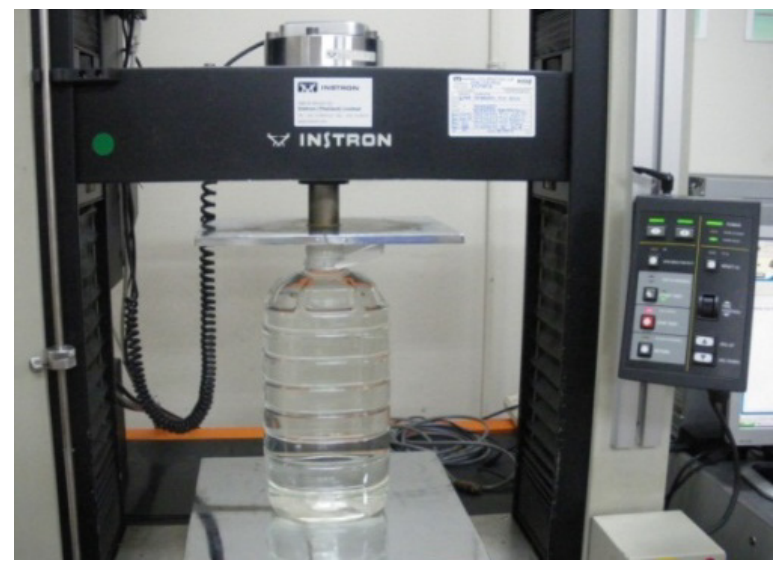

Figure 4 Top load testing on the 6-liter water bottle.

\section{Results and discussion}

\section{Model validation}

Load and deformation acquired and plotted were as shown in Figure 5. The later obtained stress cracking resistance of the bottle, $85.95 \mathrm{MPa}$, was calculated from an approximate maximum load of 344 $\mathrm{N}$ deriving from the load-deformation curve. Simulation results under identical incremental loading were evaluated, plotted and then validated against the experimental results. These results were presented in Figure 5. From the Figure, the two sets of data appear to be very closely fitted in the elastic region. The percentage of root-mean-square deviation (RMSD) was also used to measure an accuracy of simulation results and the experimental results. The obtained RMSD of $2.2 \%$ was well acceptance. Furthermore, in the t-test analysis, the obtained t-value of -0.0819 is well within the critical range tabulated in the $t$ distribution Table (-2.033 to 2.033). It can be concluded that the model prediction is in good agreement with the experimental data. Thus, the maximum load of $344 \mathrm{~N}$ in Figure 5 was able to apply for simulation to define the stress cracking resistance. The Finite Element Method of analysis was based on element equation $\{f\}=[k]\{d\}$ where $\{f\}$ is the force function, $[k]$ the stiffness function and $\{d\}$ the displacement function. The result of analysis using the ANSYS software revealed a maximum stress, or critical stress, or stress cracking resistance of $85.95 \mathrm{MPa}$. This stress value was to be applied in the bottle design. 


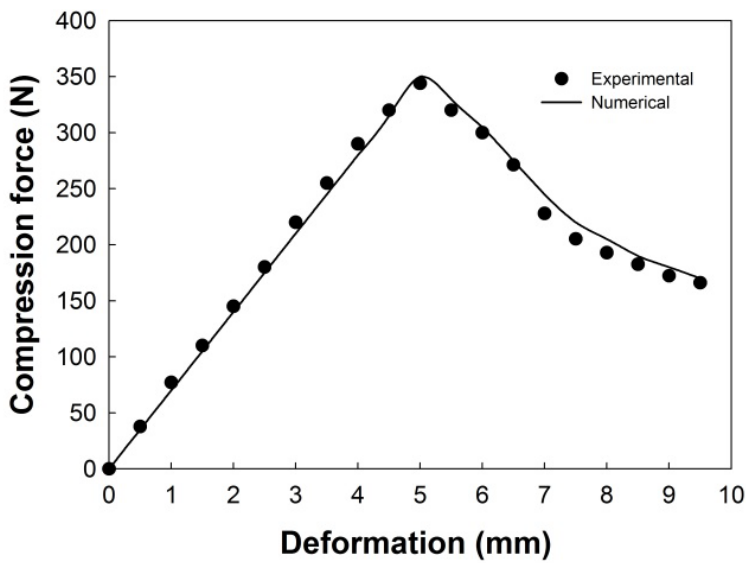

Figure 5 Comparison of numerical and experimental data.

\section{Bottle thickness investigation}

Many factors affect bottle designs, such as bottle shape [5], bottle pattern [4], and bottle thickness $[7,12]$. This study, however, had confined itself to investigate only the effect of bottle thickness, or wall thickness parameter, on a particular bottle shape and pattern because this appeared to immediately affect more the material cost. The 4-stack top load capacity requirement was used to calculate stresses on five different bottle thicknesses. The current bottle thickness was $0.500 \mathrm{~mm}$. This was reduced by an incremental thickness of $0.025 \mathrm{~mm}$ until it was $0.400 \mathrm{~mm}$; the range that failure was anticipated to occur. Variation of thickness slightly influenced the bottle weight. This was nearly negligible compared to the weight of water in the bottle. However, it was taken into account in this study for the sake of academic exercise. Table 1 showed the calculated applied top-loads to the different bottle thicknesses in the simulation. In the thickness analysis, the equivalent von Mises stresses calculated were compared with the criteria stress of $85.95 \mathrm{MPa}$. Deformations, though also measured and plotted, were observed only for their changes in physical behaviors, and not for the thickness design.

Table 1 Top-load on bottle of different thickness.

\begin{tabular}{cccc}
\hline $\begin{array}{c}\text { Thickness } \\
(\mathbf{m m})\end{array}$ & $\begin{array}{c}\text { Bottle volume } \\
\left(\mathbf{c m}^{\mathbf{3}}\right)\end{array}$ & $\begin{array}{c}\text { Weight (water + bottle) } \\
(\mathbf{k g})\end{array}$ & $\begin{array}{c}\text { Load } \\
(\mathbf{N})\end{array}$ \\
\hline 0.500 & 105.10 & 6.13 & 240.39 \\
0.475 & 100.27 & 6.12 & 240.16 \\
0.450 & 95.43 & 6.12 & 239.93 \\
0.425 & 90.59 & 6.11 & 239.71 \\
0.400 & 85.74 & 6.10 & 239.48 \\
\hline
\end{tabular}

\section{Bottle body strength and deformation}

Figure 6 showed the plotted results of bottle thickness against maximum calculated stress, as well as against maximum deformation of the bottle. It can be clearly seen that the stress value increased as the thickness of the bottle decreased; as thickness decreased incrementally from 0.500 to $0.400 \mathrm{~mm}$, the maximum stress increased from 47.48 to $95.21 \mathrm{MPa}$. At thickness of $0.45 \mathrm{~mm}$ the maximum stress was calculated to be $85.30 \mathrm{MPa}$. This was slightly lower than the criteria stress at $85.95 \mathrm{MPa}$ and the corresponding thickness is considered applicable since the external load used in the calculation is that derived from a 4-stack layer, and not the 3-stack layer as stipulated in TIS 998 standard. For a 3-stack layer loading the maximum stress of $71.13 \mathrm{MPa}$ was obtained from a recalculation using the model. This 
http://wjst.wu.ac.th

offered a factor of safety of approximately 1.2 and hence the bottle thickness could be safely reduced from $0.500 \mathrm{~mm}$ down to $0.450 \mathrm{~mm}$. The bottle volume could thus be reduced by some $8.7 \%$. It can be concluded that the bottle thickness had a more effect on the bottle strength. Furthermore, the effect of bottle thickness on the maximum stress seemed to be in accord with the previous works [6-8].

Figure 7 illustrated the stress contour and the deformation of the bottle. Higher stresses on the bottle appeared to occur more intensively at the bottle neck than at bottle ripples. At $0.500 \mathrm{~mm}$ bottle thickness the maximum shortening of the bottle was at approximately $3.05 \mathrm{~mm}$. At $0.450 \mathrm{~mm}$ this displacement was calculated to be approximately $3.45 \mathrm{~mm}$; a further shortening of $0.40 \mathrm{~mm}$ or a little over $13 \%$. Nevertheless, strength is more of a concern, and not shortening.

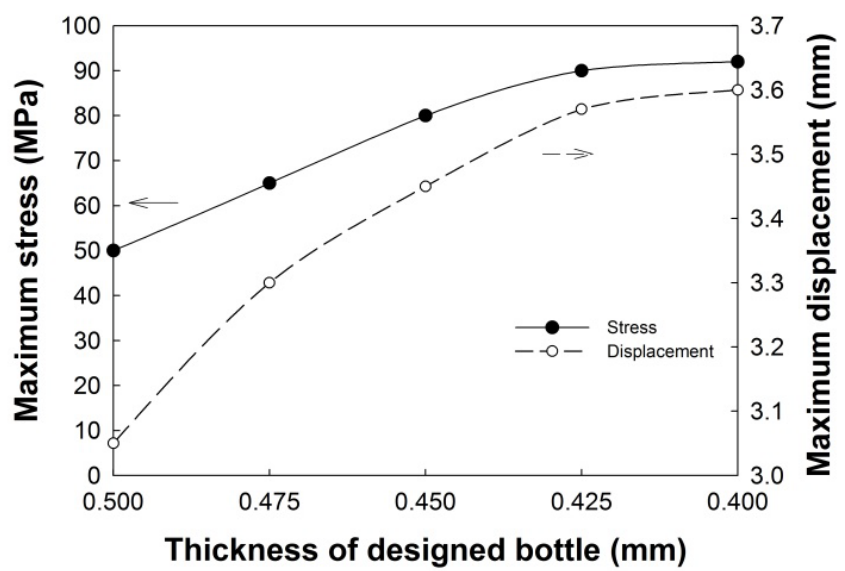

Figure 6 Maximum stress and bottle shortening at difference bottle thicknesses.

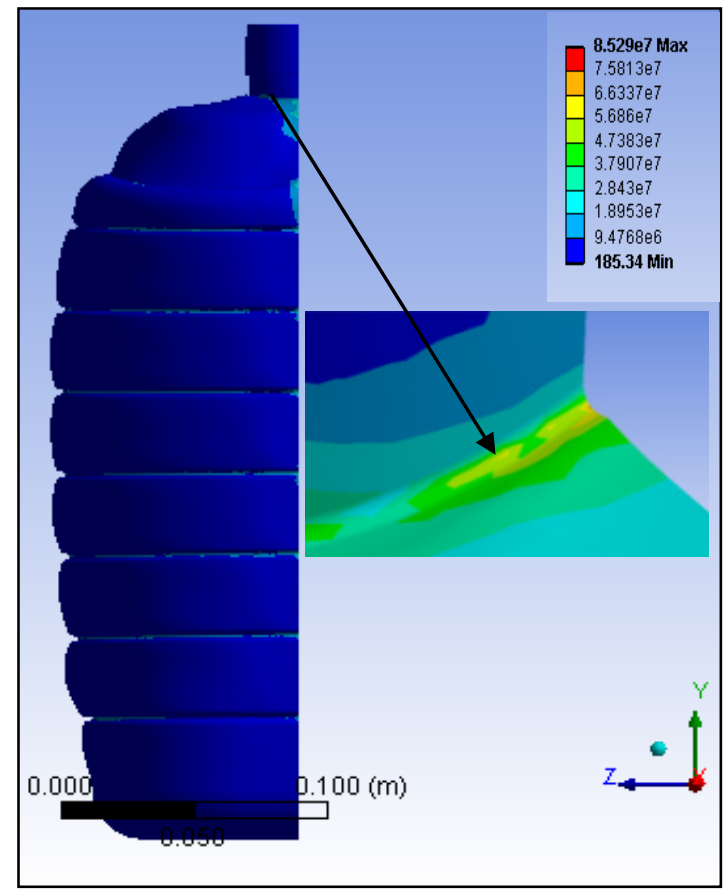

Figure 7 Stress contour of the bottle. 


\section{Bottle handle strength}

Under TIS 998 standard criteria for the bottle handle strength, the simulation result on the chosen PE bottle handle with corresponding shape and size yielded a maximum stress of $21.23 \mathrm{MPa}$ occurring at the top of the bottle handle, as can be observed in Figure 8. This stress was less than $25 \mathrm{MPa}$, the yield stress of the PE, and thus was still safe. However, the factor of safety of only 1.17 was not high. For safety consideration it was not worth redesigning in order to reduce the amount of material in the handle. Besides, the volume of the handle of $6.23 \mathrm{~cm}^{3}$ was only $6 \%$ of the whole bottle volume and any reduction to material cost should be minimal.

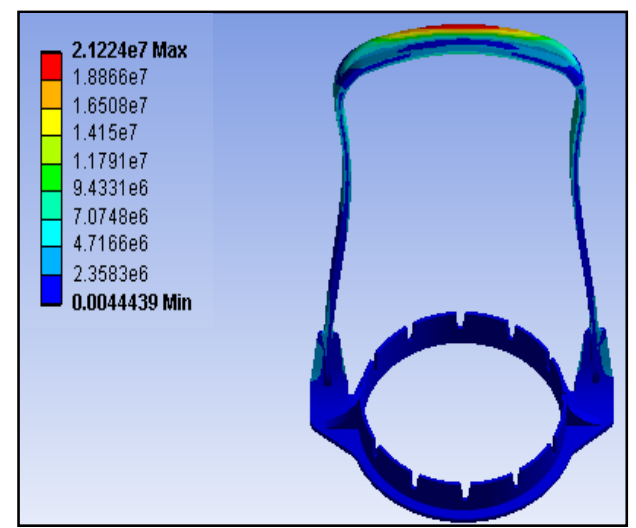

Figure 8 Stress contour of the bottle handle from simulation.

\section{Cost saving}

Costing of PET bottle manufacturing process was considered in two main stages: bottle preforming and bottle blow molding. In this research, finding of an optimal thickness of the bottle was conducted to serve the main aim of reducing the PET volume, and hence the cost. The amount of PET was sensitive during preforming design whereas during blow molding the amount of PET was already determined and could not be changed. Thus, cost saving by reducing PET volume had to be considered only in the preforming process. From the analysis, for the 6-liter water bottle strength requirements in accordance with TIS 998 standard and according to our FEM analysis, the bottle thickness that was able to be safely reduced from $0.500 \mathrm{~mm}$ down to $0.450 \mathrm{~mm}$ meant a saving of $0.012 \mathrm{~kg}$ PET material per bottle. At the present PET resin price of $54 \mathrm{baht} / \mathrm{kg}$ [20], this leaded to a saving of 0.542 baht per bottle; an $8.7 \%$ cost reduction, in line with the PET amount saved as stated earlier.

\section{Conclusions}

In this study, FEM was employed to analyze top load and stress cracking resistance of 6-liter PET water bottle, inclusive of its handle's strength. Mechanical properties and the location of stress concentration that occurred for both the bottle and the bottle handle were investigated. The bottle performance - maximum stress and deformation - from loading higher than the TIS 998 standard was derived. From the analysis, the bottle handle strength was just above the minimum requirement and further material reduction was not recommended. For the bottle body the maximum stress was around the bottle neck region. The bottle thickness can be safely reduced from $0.500 \mathrm{~mm}$ to $0.450 \mathrm{~mm}$; a 0.012 $\mathrm{kg} /$ bottle or 0.542 baht/bottle or $8.7 \%$ saving. FEM simulation can be employed to save time and eliminate most of the testing costs in the designing process. In the future, the effect of bottle thickness on the bottle strength will be further investigated in terms of the non-dimensional parameter in order to obtain deeper 
http://wjst.wu.ac.th

understanding of the fundamental physics of the problem. The effect of bottle thickness distribution may be further considered to extend this work, so that a more realistic particle impact process can be investigated.

\section{Acknowledgements}

The authors would like to thank the Grid Center of the Prince of Songkla University for the use of ANSYS software and the Thai Packaging Center for the use of an Instron machine. Thanks are also extended to the PSU Department of Industrial Engineering for permission to utilize laboratory facilities.

\section{References}

[1] National Statistical Office of Thailand, Available at: http:/www.nso.go.th/sites/2014/Pages/ home.aspx, accessed March 2018.

[2] C Bannawat. (2010), Thai Industrial Standard of Water Filled Plastic Bottle (TIS.998-2010). Royal Thai Government Gazette. Bangkok, Thailand: Thai Government Publishing Service.

[3] H Qingchun, S Wenjian, L Yanhui and W Yongsheng. Structural optimization and lightweight design of PET bottle based on ABAQUS. Adv. Mat. Res. 2012; 346, 558-63.

[4] V Gulati, P Tandon and P Kaldeep. Parameterized modeling of blow-moulds for designer PET bottles. Comput. Aided Des. Appl. 2010; 7, 479-87.

[5] G Vladić, N Kašiković, D Avramović and N Milić. Pet bottle design, correlation analysis of pet bottle characteristics subjective judgment. J. Graph. Eng. Des. 2012; 3, 9-14.

[6] CA Miranda, JJ Câmara, OP Monken and CG Santos. Design optimization and weight reduction of $500 \mathrm{~mL}$ CSD PET bottle through FEM simulations. J. Mat. Sci. Eng. 2011; 1, 947-59.

[7] F Daver and B Demirel. An energy saving approach in the manufacture of carbonated soft drink bottles. Proc. Eng. 2012; 49, 280-6.

[8] B Demirel and F Daver. Effects of preform deformation behavior on the properties of the poly (ethylene terephthalate) bottles. J. Appl. Polym. Sci. 2012; 126, 1300-6.

[9] M Allahkarami, S Bandla and JC Hanan. 3D thickness mapping by micro-computed tomography aiding design. Soc. Plast. Eng. Conf. 2015; 2015, 2574-7.

[10] T Naemsai and K Thongkaew. Optimization of geometrical factors for 6-liter PET bottle using finite element and response surface methodology. Ladkrabang Eng. J. 2014; 31, 43-8.

[11] SH Masood and V KeshavaMurthy. Development of collapsible PET water Fountain bottles. J. Mat. Process. Tech. 2015; 162, 83-9.

[12] B Demirel and F Daver. Optimization of poly (ethylene terephthalate) bottles via numerical modeling: A statistical design of experiment approach. J. Appl. Polym. Sci. 2009; 114, 1126-32.

[13] L Sun, J Zou and K Chen. FEM-based research on molding parameter analysis of the PET beverage bottle. Appl. Mech. Mater. 2014; 488-489, 121-4.

[14] AA Krimpenis and JG Tsakanikas. On systematic CAD/CAM modeling of blow molds for plastic bottles. Solid State Phenomena 2017; 261, 448-55.

[15] ZJ Yang, JE Harkin, GH Menary and CG Armstrong. Coupled temperature-displacement modeling of injection stretch-blow moulding of PET bottles using Buckley model. J. Mater. Process. Tech. 2004; 153, 20-7.

[16] ANSYS Software, Available at: http://www.ansys.com, accessed January 2018.

[17] RC Juvinall and KM Marshek. Fundamentals of Machine Component Design, $4^{\text {th }}$ ed. John Wiley \& Sons, New Jersey, USA, 2006.

[18] Instron Machine, Available at: http://www.instron.co.th/wa/product/5900-Series-MechanicalTesting-Systems.aspx, accessed February 2018.

[19] RE Walpole, RH Myers, SL Myers and K Ye. Probability \& Statics for Engineers \& Scientists. $8^{\text {th }}$ ed. Pearson Prentice Hall, London, UK, 2007.

[20] Thai Plastics Industry Association, Available at: http://www.tpia.org/stat/graphindex.asp, accessed March 2018. 